Jui-Pi Chien

\title{
Fashionable yet strategic similarities: Diego Velázquez's creative consciousness seen through Saussurean-Hegelian composite approach
}

\begin{abstract}
This study explores some ways of perceiving and interpreting the Spanish painter Diego Velázquez's proposition as regards the status of painting. It draws on Saussure's and Hegel's approaches to creative consciousness, in which a subject is supposed not only to negate the distinctions between the past and the present, but also to open up his/her thoughts for the future. This paper begins with a series of questioning as regards a compositional scheme that Velázquez included in two of his major works, Las Meninas and Fable of Arachne. First of all, it is argued that it is essential to recognize the ambiguity of the actual object of representation in these paintings. Then Saussure is conjoined with Peirce in the light of Jakobson's charged interest in decoding artifices devised in the arts. Such a mingled approach helps to expand our perception by stringing Velázquez's works together with those of his forerunners. In the first stage of interpretation, his technique is appreciated as a result of the need to overcome rivalries or surpass previous achievements. However, in order to look deeper into the painter's mind, this study introduces another stage of interpretation by drawing on Hegel's radical notion of memory. This second stage underlines the paradox that we cannot really get rid of the past when coming up with any kind of genuine innovation. Velázquez's thoughts are therefore revealed as a continuous process of piecing together and modifying desirable elements found in his forerunners. Finally, both interpretations are integrated within the larger context of evolutionary epistemology that actually allows the coexistence of different truths within our consciousness. This context helps extend our perception to certain artists beyond Velázquez's time and environment. It is argued that Velázquez's proposition actually questions the thorny task of achieving objective representations. It is also discovered that his proposition has invited some collaborations in which artists engage with pleasure with the negativity between seeing and thinking.
\end{abstract}

Keywords: painting, artifice, perception, memory, negativity, creative consciousness DOI 10.1515/sem-2014-0034

Jui-Pi Chien: National Taiwan University. E-mail: jpchien@ntu.edu.tw 


\section{Conceiving of Las Meninas and Fable of Arachne as a continuum}

Let us juxtapose two canvases that depict two studios: the one in a royal palace and the other in a spinners' workshop (Figure 1). On our first encounter with these paintings, we may not be clear about the true identities of these figures, but in terms of pictorial quality we observe that both studios are divided between light and shadow. We intuitively want to linger over the areas that are well-lit, and marvel at certain figures' visages, costumes, and gestures - they definitely appear vivid and pleasant to our eyes under the painter's fine use of light. However, the shadowy sections prevent us from sitting back and relaxing. From time to time, we suffer from a pang of conscience: why are we ignoring the shimmering light reflected from the mirror (at the back of the palace room) and the spinning machine (at the front of the workshop)? We wonder: where does the light emanate from under the cover of shadowy darkness? How is it relevant to the rest of the scenes? Did the painter make a mistake as regards the physical law of depicting objects? Or, is there an intricate message that the painter seeks to communicate?

As soon as we start questioning such a unique device, we assume the position of a dutiful and industrious spectator. We start to study the figures that appear like viewers of the whole scenes from within these paintings. The courtier (backlit figure) standing on the staircases in Las Meninas and the maid on the right of the elevated platform in Fable of Arachne seem to have a complete view of the situations: (1) they witness the painter at rest and the spinners at work; (2)
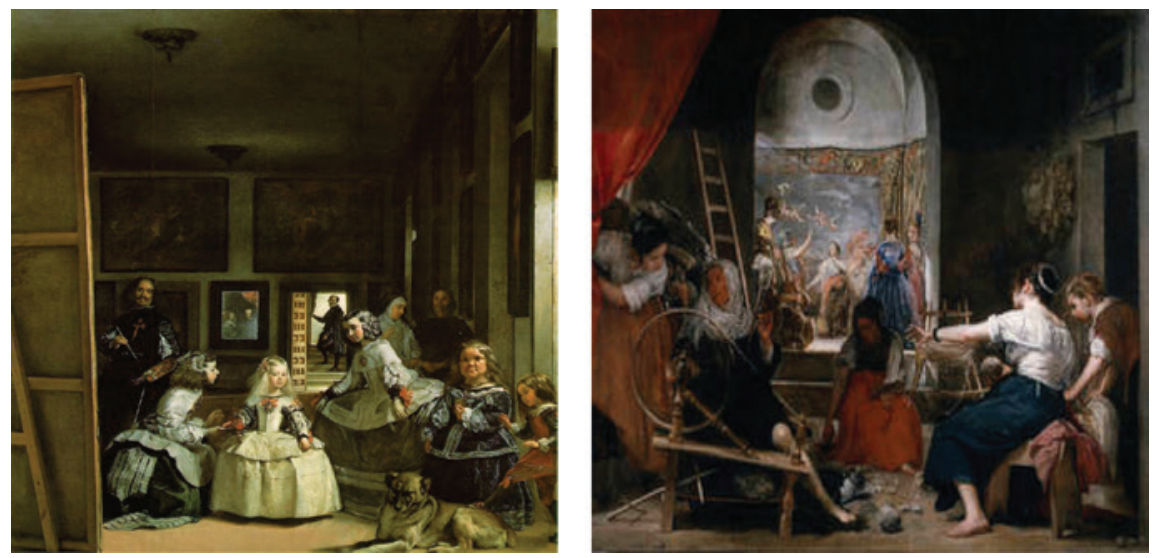

Fig. 1: Comparison and contrast between Las Meninas (1656) and Fable of Arachne (1657) 
they observe the arrangement of models in the atelier and the strangely heated debate occurring on the platform; (3) most of all, they appear like a threshold that shifts between seeing and not seeing the actual works achieved by the painter and the spinners - respectively displayed on the large canvas before the painter and as the tapestry at the back of the workshop. Furthermore, in order to reach these inner viewers, we set our eyes along the diagonal matrix stretching from the lower left to the mid right. On our path of moving further into the deep recesses created by the painter, we gather some key elements that constitute the birth of a painting: (1) an artist, (2) his/her object of representation, and (3) his/her expected (or ideal) viewers.

Although we have been given the titles of these paintings, their subject is still very much hidden, or rather, in absentia, on our first encounter with them. We as external viewers are overwhelmed by the ambiguity as regards the object of representation. In the atelier, the object is undefined and opens up several alternatives: it can be (1) the princess and her entourage; (2) the two figures reflected in the mirror; and even (3) the two dark paintings displayed on the same wall as the mirror. In the spinners' workshop, the tapestry is visible but unsettling: it is behind two quarrelers who appear incompatible with the maids and the spinners. Nevertheless, the mirror, the two dark paintings, the tapestry, and the two quarrelers appear fairly close to the viewers within the paintings. Such a unique design - a close proximity between objects of representation and viewers within the paintings - appears as the key to what the painter seeks to communicate. So it appears that we should align ourselves with these viewers and their horizons in order to solve the ambiguity of the intended object, and move on to explore some of the messages hidden in the images.

However, the dilemma persists! On the basis of our anatomy of the scheme of composition, we cannot figure out why the painter has made the potential objects so close to each other but so vague in appearance. It is as if the painter as the sole governor of his own art invites us to engage with this problem. Fortunately, as external viewers, we have the advantage of "comparing and contrasting" works of art - we are able to detect differences between earlier and later works, and hopefully sort out some twists and turns in the painter's uses of brushstrokes (Pächt 1999 [1986]: 104). A radiograph of the painting Las Meninas reveals that Velázquez replaced a previously painted female figure as his own - the artist's charming self-portrait was actually missing in the earlier draft (on the left in Figure 2). The female figure - like the painter - gazes at viewers as well, but she appears more like a compatible part of the princess' entourage. The stark revision of the figure standing before the canvas is stunning: the other elements in the finished painting do not differ much from those in the radiograph. Such a revision discloses the painter's second thoughts: he may have intended to emphasize his authority and 

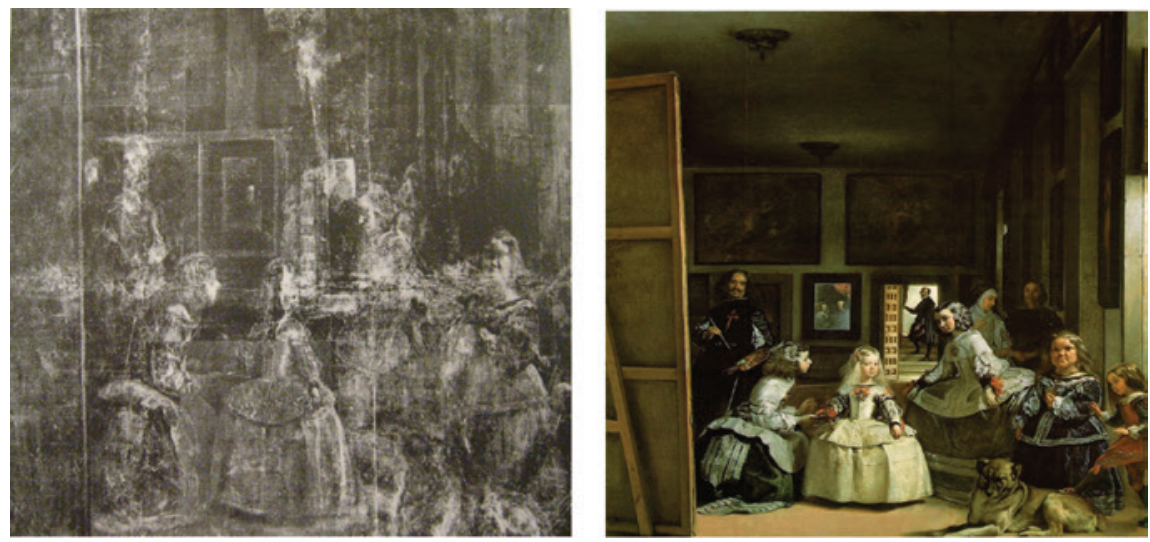

Fig. 2: Comparison and contrast between the radiograph and the finished painting (Brown and Garrido 1998: 184)

position more than the service of painting royal portraits. This decisive move resulted in a break between the painter and these lovely-looking figures in the foreground (the presumed subject of the painting), but has emphatically associated the self-portrait with those eerie-looking objects in the background.

There is no denying that Michel Foucault's analysis of Las Meninas has enticed us to perceptually and intellectually engage with those sensory forms shown on the surface of canvas. According to his philosophical contemplation, the painting illustrates a crevasse in the history of epistemology, which deals with the incompatibility between the visible and the invisible forms. What the painter is actually working on is forever denied to us, and we as viewers can only gather some rough ideas about it from the mise-en-scène around the canvas facing the painter at rest. Such an interpretation is brilliant, but it still leaves us some puzzles to work out. We wonder about the intended source of power that constitutes the so-called "center" of composition or representation (Foucault 1988: 103). Can it be true that Velázquez simply portrayed himself as a servant of the king and queen, as a loyal court painter, or was he actually declaring his own authority - encoding his private agenda - over the trade of painting? In developing his own discourse about the epistemological break occurring in the seventeenth century, Foucault circled around the unique position of the images of the king and queen reflected in the mirror. However, he simply shied away from the two paintings hung on the same wall due to their hazy darkness. By discriminating between the mirrored images and the two ill-defined paintings assuming that the former is more complete than the latter in the procedure of 
representing - Foucault unfortunately ignored the inherent logic of Velázquez's technique for carrying out this part of the painting.

In terms of painterly practice, there is actually not much distinction between the shimmering mirror and the gloomy paintings - Velázquez applied the same method of creating "softness" and "blurriness," done quickly with his brush loaded with diluted and liquid pigments (Brown and Garrido 1998: 192, 194). Such an approach creates an interplay between illusion and reality among viewers: when taking a closer look at these details, we perceive merely colors and brushstrokes; when keeping a certain distance of viewing, we recognize them as unique totalities that suggest certain stories. This technique is valued as the fruit of the painter's “intellectual maturation” later in his career (1998: 19). He is thought to have planned well before applying brushstrokes on individual areas so as to create certain effects of reality. In addition, supplied with records and documents, we come to realize that those fuzzy images in the background refer to real people and famous paintings: the two figures in the mirror are Philip IV and his wife; the two dark paintings are copies of Flemish painters' masterpieces - Rubens's Minerva and Arachne on the left and Jordaens's Apollo and Marsyas on the right. Nevertheless, the painter's self-portrait looking out at us suggests something more than verisimilitude (Nancy 2006). This image actually conceals some curious thoughts about the trade of painting: (1) it elaborates on the tensions inherent in the process of creating an artwork; (2) it draws on the thorny subject of rivaling with forerunners; (3) it revises certain established norms and looks out for a new trend or tendency in art history. The idea of making progress out of limited resources - such as lines, forms, and colors - finds its strong parallel with the image of the old spinner along with her fast-running machine. Through these images - the painter's ad hoc self-portrait and its variation in the context of spinning - both of which loom large as the potential object of representation, we reflect on how we can connect the painter's pictorial performance, thoughts, and technique to other practices in art history.

\section{Mingling of Saussure and Peirce for our analysis of intriguing artifices ${ }^{1}$}

In conceptualizing the creation and interpretation of the arts, Roman Jakobson parted ways from Emile Benveniste upon the issues of code and meaning. While

1 Part of this section (2) appeared previously in another paper by the same author: Chinese Semiotic Studies 7.1 (Sept. 2012), pp. 98-101. 
Benveniste criticized the unpredictable nature of art, the meaning of which goes beyond the restriction of code, Jakobson urged that we should consider both artists" "faithfulness" to specific codes and their "revolts" against rules, schools, or styles (Benveniste 1985 [1969]: 239; Jakobson 1987a: 451). Being unable to appreciate the shifty and unruly nature of arts, Benveniste averted from rationalizing the flexibility of signs in the context of arts. Rather, Jakobson in turn proposed to use the concept of "artifice" to mediate between Saussure and Peirce and to make the point about their congeniality - the "artistic character" that underlines the process of endless semiosis (1987a: 451). His approach illustrates that the binary and the triadic modes of signs can find their common ground upon the scheme of time (roughly divided as the past, the present, and the future), and he reminded us of the fact that Saussure's scope is no less future-oriented (esse in futuro) than Peirce's (1987a: 452). Jakobson's mediation helps us imagine the breaking down of a triad into two binary oppositions, which actually reveal two ways of actualizing the arbitrary relation in the context of arts. On the one hand, the arbitrary relation is contiguous and similar, and is paralleled with the factual and "indexical" (referring to something in reality) on Peirce's scheme. On the other hand, the arbitrary relation is factual but "imputed" (attributable to certain styles or types), and is thus relevant to the "symbolic" in Peirce (1987a: 451; Figure 3). Although Jakobson was aware that the two pioneers had pursed different intellectual or philosophical lineages, he came up with this model intended exclusively for the needs of analyzing the arts.

Therefore, when considering both the visual arts and poetic language within this composite model of four-part entity - keeping in mind also that the Peircean iconic (some latent ideas not yet expressed) is their shared point of departure we realize that the revolts in art history are subject to ways of devising attribut-

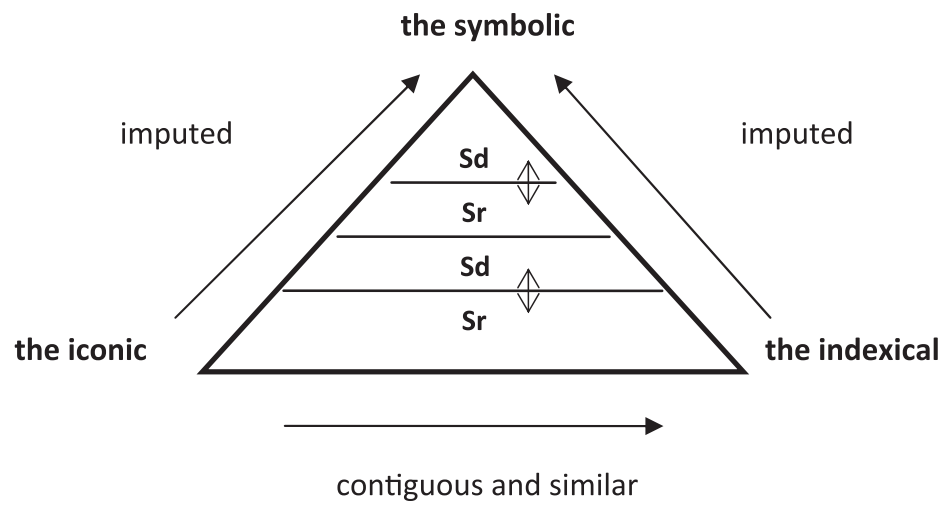

Fig. 3: Jakobson's mingling of Saussurean and Peircean models (illustrated by the author) 
able similarities. Two pieces of artwork may look quite similar to each other, but there are still some details which defy the resemblance proper. Instead of assuming a complete destruction of specific codes, we observe how artists have deviated from these codes in their gradual but creative fashions. In terms of temporality, the devices they have developed remind us of certain details already depicted in the past, guide us to perceive what is shown right in front of us at present, and even enable us to imagine what is going to occur in the future; in certain cases, they create atemporality which confuses our distinctions of time. More often than not, in both narratives and paintings, some creative revisions simply appear as "redundant" and "superfluous" details, which render it difficult for us to make references or to judge their importance (Jakobson 1987b: 25-26). Jakobson's innovative reading of the arbitrary relation and his mingling of Saussure and Peirce help putting art and language on an equal footing: they both manifest results of psychological, conceptual, and intellectual activities which create, argue with, or battle against conventions. Moreover, based on this argument, Jakobson enlarged the reality of signs as a matter of intention, perception, and interpretation. He made the crucial point that our interpretations of an artist's deliberate efforts in creating new forms should replace period styles those prêt- -porter general features of certain trends or periods - summarized by art historians (1987b: 25). Seen from the perspective of this composite model, the reality of signs also emerges in the form of some "precise values" as we make our own individual and private decisions as regards how we approach or deal with specific codes and artifices (1987b: 20).

By bringing together Jakobson, Peirce, and Saussure under the notion of the poetic and artistic nature of semiological systems, we are able to appreciate in Saussure some ideas relevant to the creation and interpretation of endless deviations and disputations. The specific conceptual tool in Saussure, which intriguingly elucidates our reception of clever, cunning, or deceiving devices, is negativity. In his orangery manuscripts, Saussure defines it as a kind of "fiction" (or "invention"), i.e., a mental capacity that deals with differences without the constraint of time and solid reference points (2006: 42). Such mental power constantly introduces new semantic networks and propositions into a system by putting into "opposition" terms of different attributes (2006: 49-51). In these networks, all the terms become the seeds of each other: what is observed here and now can have appeared before and may still emerge in the future. Negativity reveals a sort of creative consciousness which tries all means to shape or build up the present. It does not bother to worry whether such a construction - already an opposition and revision - is for the better or the worse. The precise value of such a system does not derive from the general (non-artistic) scheme of time, in which a system is supposed to become more or less improved with the passing of time. 
The value of the semiological (artistic) system simply hangs on with or circulates around some sudden constructions, new oppositions, and constant revisions, which aim at multiplying networks and extending the boundaries between (grammatical and conceptual) categories. The semiological system is actually prominently featured in modifying forms and assimilating new (and unexpected) relationships at the same time. Therefore, in the light of Saussure's emphasis on the feature of a constantly changing system, the impact of invented oppositions upon our categorical way of thinking and perceiving not only claims the central object of study in semiology, but also provides us with a novel approach, or rather a framework, to explore some minute yet deliberately-modified details that artists have created.

\section{Staging of transdiscursivity between Velázquez, Rubens, and Titian}

Perceived as a semiological system, the two paintings we have been observing (Figure 1) appear like an invented opposition, mainly due to the contrast between light and shadow in their backgrounds. They also exemplify the transition from one state of consciousness to another, within which Velázquez thought over how he would modify other systems, namely, his forerunners Rubens and Titian. Focusing on this continuum (between shadow and light), we find the theme of rivalry even more prominent - Flemish painters' achievements have been diluted by the Spanish painter's sophisticated technique. By manipulating Rubens and Titian's Ovidian depictions and inserting them into his major works, Velázquez appears to have devised a proposition as regards the trade of painting. We need to look into how the painter devised his new technique to go along with his intellectual thinking and reasoning. While we are going back in time with these semiotic concerns in mind, we aim to discover: (1) the painter's awareness of the past (on the basis of his dealings with Rubens and Titian); (2) the intelligibility of his technique in blurring the distinctions between the past and the present (in accordance with his interpretation of Ovidian stories of artistic rivalry); (3) the power of such a technique in inducing potentially new relations between the past and the present, which points to a new discourse of painting for the future. This approach we are introducing into the discussion of such a system sheds light on the truth of the inner logic, or rather, the new position of reading and interpreting art history that could have occurred within the painter. It should serve our purpose of revealing the breadth of mental horizons in which the painter imagined the opposition and dissolution of the boundaries between the past and the present, i.e., the way he inserted his position into the continuum of history. 
The image most charged with Velázquez's new idea shows the dispute between Athena and Arachne in Fable of Arachne: they are arguing and standing on equal footings before the tapestry which is presumably Arachne's work. In addition to the contrast of lighting - eerie darkness in the background of Las Meninas while glittering brightness in that of Fable of Arachne - Velázquez modified the mode of interaction between the two mythological figures in Rubens's drawing (1636-1637). Rather than threatening to hit Arachne on the forehead, Athena in Velázquez's work is conversing with the self-righteous but talented weaver. Although the goddess appears with a right hand pointing to the sky, it is more likely that she is claiming her authority than preparing to hit the mortal. However, the flux of time in Velázquez's treatment of Rubens is fixed and frozen (as in the background of Las Meninas) - we cannot really see how the other weavers are operating their machines due to the darkness and blurred contours. We are forced to concentrate our attention on Athena's gesture, which is generally believed to take place a moment just before the climax of hitting narrated by Ovid. Nevertheless, in creating his own Fable of Arachne, Velázquez vividly portrayed the coexistence of the past, the present, and the future: a completed artwork shown as his own treatment of Titian's Rape of Europa (1559-1562); a debate between Athena and Arachne which occurs simultaneously with the weavers laboring in the foreground; the debate will still go on considering the rapid movement of the spinning machine.

Such a new formulation is completely Velázquez's own - the scene of conversing and debating does not appear in Ovid's narration at all. Moreover, Velázquez's composition goes beyond the aesthetics of selecting specific moments from narratives in depicting and appreciating history or allegorical paintings. The new proposition that he devised through his thoughtful mixture and modification of Titian, Rubens, and Ovid is two-fold. On the one hand, he revived the features of speech, equality, and tolerance of different tastes that are missing in Ovid's narrations of artistic rivalry. On the other hand, he transformed artistic rivalry into a matter of conscience - an endless battling within one artist divided between being ready to receive, absorb, and pay homage to forerunners (some prototypes, themes, or techniques they have chartered in art history) and nonetheless insisting upon his/her own original designs. It appears that Velázquez has tactfully and impressively blurred the boundaries between the images of Arachne and Europa - some scholars even wondered whether they share "the same plane" (Portús 2007: 285-286). Focusing on this composite image that the painter devised, we find that (1) Arachne's apron in red color appears like an extension of Europa's fluttering garments of the same color in its slightly diluted texture; (2) Arachne's left hand is missing, but Europa's foot, a tiny part of which appears adjacent to the apron, gives the illusion of a hand. Other than these, in terms of 


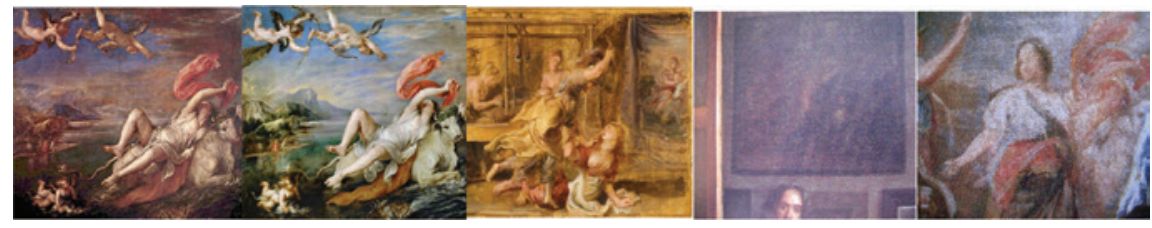

Fig. 4: A chronological chain of works on Europa and Arachne (Titian 1559-1562; Rubens 1630; Rubens 1636-1637; Velázquez 1656; Velázquez 1657)

iconographic breakthroughs, the designs of the two figures were already revisions of other texts: (1) Titian presented Europa as lying lopsidedly on the back of the bull rather than riding on it; (2) Velázquez invented Arachne's dignified standing position (on the far right in Figure 4) rather than following the stereotype of a victim (or a spider) sprawling on the ground.

The fact that Velázquez returned to the "prototype" by Titian with an eye to creating his own image implies his intention of restructuring our memory (Pächt 1999: 117). We are invited not only to forget about Rubens's copy of Titian's Europa (appearing pale and white; 1630) and Rubens's drawing of Arachne (provoking feelings of horror and defeat; 1636-37), but also to imagine through Velázquez's treatment of Europa a completely different fortune of Arachne on the basis of a cozy color scheme and exuberant atmosphere (1657; Figure 4). The self-determined scheme that governed Titian's Poesie series dedicated to Philip II was to evoke our sympathy for victimized figures, just as much as Aristotle in his Poetics - a rediscovered and much-read text during the Italian Renaissance - emphasized our mental responses of "pity and fear" to the falls of heroes and heroines (Puttfarken 2003). Moreover, Europa in Titian's composition is thought to be experiencing "a reversal for the better" (Puttfarken 2005: 174): her jolly good fortune of giving birth to Minos on Crete is preceded by the deprivation of virginity and homeland; her ecstasy of uniting with Zeus is foretold by her eyes turning upwards and her position on the bull. Setting our mind against such a hermeneutic backdrop, we start to become alerted to Velázquez's intricate scheme. Intelligently, he drew on Titian as a new context to overcome the rivalries - that between Titian and Rubens (Lope de Vega judged Rubens as the new Titian [Portús 2007: 289]) and that between Rubens and himself (as fellow court painters) - so as to fuse his originality with Titian and come up with a new scope of storytelling. His sympathy for Arachne to a large extent revised Ovid's derogatory tone of the same figure ("in her desire for the foolish palm of victory, she rushes to her fate" [Ovid 2010: 144]).

Velázquez's hidden rivalry with the Italian and Flemish conventions is seen as a "tranquil revolution" ("Sa technique, qui avait émerveillé Rubens et les Ital- 
iens, poursuit sa tranquille révolution" [Lassaigne 1952: 68]). The very fact that the painter seldom improvised but always planned intriguing compositions and color schemes earns him the reputation more of a "pensive philosopher" than an instinctive artist (1952: 52). His close symbiosis with the two conventions enabled him to polish his technique while opening up the possibility of endless semiosis in his works. His game - played through such various strategies as darkening, brightening, blurring, and blending distinctions - finds a solution for the impasse of depicting history paintings after the Renaissance. In the first place, he keeps a critical distance from the order of narratives in written texts so as to avoid banal or stereotypical compositions. Rubens obviously reads Ovid so closely that through his works we simply observe a correspondence between narratives and paintings - our liberty and pleasure of imagining and exercising our intellect is considerably constrained. Moreover, in terms of the growth of intellect, Velázquez allows viewers to exert their mental power of penetrating and recreating things seen on the surface of canvas. Each image or detail structured within a deep and unifying space - whether well- or ill-defined, shining or gloomy - can be associated and dissociated with another for a specific interest or purpose of arguing and reasoning. Viewers have the advantage of staging their own dramas of "magical metamorphosis" ("selon un processus de métamorphose réellement magique" [1952: 51]): we are invited to speculate about the relations between images through a complicated process of negating, transforming, and transcending.

\section{Mingling of Hegel and Saussure to engage with Velázquez's concrete thinking}

\subsection{Conditions of bridging Hegel and Saussure ${ }^{2}$}

Recent studies of Hegel have recognized some reflections upon language, manifested in the notion of "speculative sentence" (der spekulative Satz) or "proposition," as the key to reinterpreting negation, sublation, and the absolute in Hegel's system (Surber 2006: 11-13; De Man 1982: 766-767, 775). According to these new interpretations, Hegel introduced a crucial change into his system through his discussions of language: the functioning of language is no more a mediation between the inner and the outer worlds; it is rather the inner speculative traces that level philosophical and nonphilosophical (natural) languages on the same

2 This section (4.1) appeared previously in Chinese Semiotic Studies 7.1 (Sept. 2012), pp. 103-104. 
formula of subject and predicate. By focusing on the functioning of language in our inner world, Hegel reinforced our thinking as a "self-determining” process that constantly shifts from one state of consciousness to another (Surber 2006: 12). We can actually shed some new light on the problem of inert continuum ("the movement of history towards its inevitable conclusion" [Lotman 2009: 158]) - an illusion assumed to exist in the typically teleological reading of Hegel - by looking into the ways that Hegel elaborated on the intrinsic uncertainty or disjunction of language, consciousness, and representation. It is based on the shared purpose of theorizing "consciousness" as a matter of (philosophical) speculation and (linguistic) innovation that we seek to bridge Hegel and Saussure in terms of a certain epistemological continuity between the early and the late nineteenth centuries (De Saussure 2006: 4; Surber: 2006: 1).

Specifically, Hegel in his Philosophy of Mind (the third part of Berlin Enzyklopaedie) called for a new context delineated by notions of intellect and intelligence so as to describe well the functioning of signifying. As he revitalized the trope of allegory with its imagistic, sensory, and imaginary traits in particular, he thought the conventional sense of reason fails to do justice to his purpose of ridding allegory of the misconceptions that have surrounded it. Within the realm of rational thinking (reason), our consciousness recognizes no more than an identity between a form and its content (for example, allegory was thought of as a specific personified figure in religious arts), while that in intellectual thinking (intelligence) pushes for the "disintegration" or "dissociation" of the two planes (Hegel 2010 [1817]: 184, 194, 204; Jameson 2010: 124). Hegel deemed some sort of rigorous thinking about paradoxes necessary in order to appropriate figurative tropes as a part of his aesthetics. While aiming to go beyond the non-contradictory worldview advocated by his predecessors, he was also revising the nature of artistic creation and interpretation - considering the fact that his notion of representation is also liable to be conceived as "picture-thinking" (Jameson 2010: 120). Just as much as Saussure emphasized the unity of a sign, which is heterogeneous in itself, Hegel considered the synthetic and composite totality of allegory. In the context of intellectual thinking, allegorical consciousness "freely" subsumes and combines individual images - it illustrates the self-determining process through an “ensemble” of distinctively different details (Hegel 2010 [1817]: 192-193).

\subsection{Memory conceived as an intelligent way of making connections}

The schematic procedure that Hegel illustrated for the allegorical or any signifying practices follows three steps: (1) we involuntarily intuit things as images in 
our mental space; (2) we manage to universalize the contents of the images in accordance with our subjective needs such as fantasy or imagination; (3) we transform what we have imagined as memory - a unity of perceiving subjects and perceived images - so as to start thinking about or arguing for our representations (Hegel 2010 [1817]: 185-186). Moreover, Hegel thought the crucial factor of language - functioning in such temporally and spatially diverse forms as speech, grammar, and writing - starts to exert its power at the second stage, i.e., while we are imagining. The linguistic factor was thought to negate our perceptions, and thus gives rise to "a second or higher reality" of our representations (2010 [1817]: 194-195). By inserting his observations about language into his discussion of imagination, Hegel recognized the blending of fantasy and sign, i.e., "sign-making fantasy," as our fundamental capacity of developing thoughts from representations (2010 [1817]: 190-192).

Compared with the theoretical models of brain anatomy conceptualized in the Middle Ages and the Renaissance, the procedure that Hegel illustrated appears to have followed the "three-principle division": among the three welldefined ventricles, the compartment of memory was always preceded by those of imagination and judgment (Gross 1999: 33). Memory as shown in these classical models was assumed to function as a storage house of our experiences - both sensorial and intellectual materials. However, in order to orient our thinking towards potential developments in the future, Hegel made a drastic move by ridding memory of the loads of sensations, words, and representations. He wrote against the quantitative and mechanical sense of memory (such as mnemonics) while associating our memory with the quality of "organic" and "concrete" thinking that constantly creates connections between thoughts (Hegel 2010 [1817]: 203, 517). Memory in such a scheme functions like a threshold (rather than a specific area in our brain), the intensity of which would enable us to sort out some trains of thoughts - to observe their self-unfolding - by way of negating or sublating their boundaries (2010 [1817]: 202, 514). ${ }^{3}$

3 Merleau-Ponty, in his essay on the benefit of bridging Saussure and Hegel in interpreting the arts, judged "the Hegelian dialectic" as a graceful approach (1993: 110). He grounded his affirmation upon Hegel's revised notion of memory, which matters more in renewing than in summing up the past (1993: 95-96, 116). Nevertheless, he slightly biased against speech or poetry - he thought there is a stronger tendency of mapping the future in painting (1993: 116). According to both Saussure and Jakobson, within the realm of an artistic semiological system, both painting and poetry can be equally powerful in breaking away from the past. 


\subsection{Reinterpretation of Velázquez's self-portrait along with his train of thoughts}

In the light of Hegel's revised notion of memory, our creative consciousness constantly deals with contradictions that arise from the disjunction between the past and the present. Even though our intellectual thinking serves to negate sensations, words, and representations that we gathered from the past, they do not vanish completely from our mind - they more or less mingle with our perceptions either in the moment or in the future. The crux of the matter is rather that we cannot remove from our mind what we have actually experienced ("I have seen this") - we always carry with us the materiality of our past irrespective of the power of sublation (Hegel 2010 [1817]: 184). Since our mind is able to level the past and the present on the same horizons, our attention seeks to "slice" desirable portions of the past and then modify the cuttings in accordance with a specific viewpoint at present (Bergson 2007 [1903-1923]: 24-25, 179). Such a fashion of reinventing the past - creating modifications and new discourses rather than following the established truths in general history - renders the knowledge we are gaining from our problematization of Velázquez's self-portrait contextspecific. Some entirely different or alternative truths may emerge ("it could have been") even though we still work with the same given materials (2007 [1903-1923]: 22-23).

The chain in Figure 4 illustrates a historical sequence as regards how certain painterly images of Europa and Arachne evolved from one hand to another. This order in general gives the impression of artistic rivalry, a subject which has been well-received in art history. Nevertheless, we now restructure this chain radically for the benefit of looking closely into Velázquez's unique world of thinking (his inner logic) and working procedure (Figure 5). Our rearrangement of the sequence also induces a semantic shift of the way we are interpreting the rare mixture of Europa and Arachne along with the painter's self-portrait. We start to understand and empathize with the painter in his predicament: (1) it is more

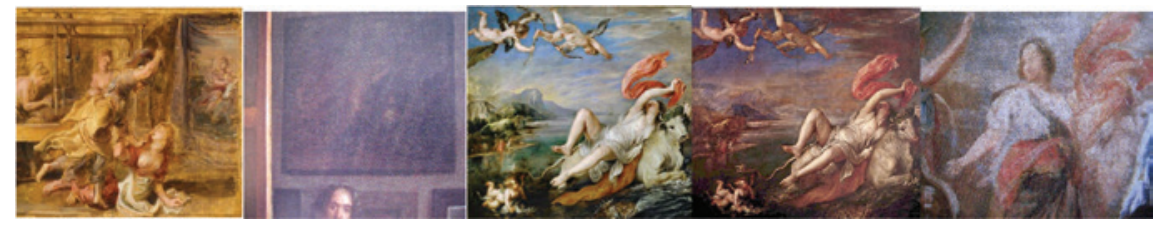

Fig. 5: A train of thoughts within Velázquez's creative consciousness (Rubens 1636-1637; Velázquez 1656; Rubens 1630; Titian 1562; Velázquez 1657) 
about the hardship of achieving objective representations than declaring power and authority; (2) the painter cannot dispense with the forms and colors his forerunners have founded; (3) in Hegelian terms, his creative consciousness is always torn between rational and intellectual thinking. Basing our perception on these constraints that we recognize from a new angle, we will discover how Velázquez engages with the fortune of painting by aligning himself with his forerunners.

To begin with, a challenging image that Velázquez came across is Rubens's drawing. He chose to rid this image of the sensations of horror, defeat, and cruelty, but still preserved the form of Athena's body leaning forward (including her right hand) together with those of Arachne's head and breasts. Such a treatment reveals that Velázquez was cautious about not deviating from the pictorial moment selected by Rubens - the moment just before Arachne became a spider. This moment shortly before being beaten on the forehead somehow retains Arachne in her human form - something that matters in considering a new discourse of painting. Moreover, in order to bring into his own work the image of Europa, he compared between Rubens's and Titian's color schemes. He adopted the sky that appears clear and bright in the background of Rubens, while imitating the rosy hues of flesh and blood found in Titian. Nevertheless, he put aside Titian's stylized sunset in which the sky appears dark and foreboding. Finally, he brought together Athena (whose remarkable hand already appears in Rubens), Europa and the bull (whose colors refer back to those in Titian), while weaving with the latter a new form of Arachne (which gives the look of a modern young lady yet evokes our memory of Titian [Wedmore 1888: 19-20]).

Through such an arrangement of interlocking sensory forms, Velázquez managed to bring the past close to the present within his field of vision - Rubens and Titian were more or less useful on his horizons. However, the glorious standing position of Arachne came as a real surprise (her lower body was after all hidden in the dark previously)! Soon after the painter freed himself from the feelings of tragedy implied in Rubens, Titian, and Ovid, there occurred in his mind a huge leap or detour as regards his thoughts about painting. His change of mind appears as drastic as that in human evolution: Arachne was no more an ape-like creature, which stays close to the ground. Rather, she gained the pride and complacency of a homo erectus, who is able to see far and away under a clear sky. Her new position and vision as well as Velázquez's self-portrait speak up for the autonomy of painting from the standpoint here and now (la vie vécue [Wedmore 1888: 20]: what the painter actually experienced; what he actually painted). Velázquez's thinking about the value of painting was spiraling upward along with his pleasure of creating a mixed look of Arachne, which is memorable yet modern. 


\section{Towards an evolutionary epistemology of the arts}

\subsection{Saussure and Hegel enlarge on the complexity of our perception}

Apart from Foucault's recognition of Las Meninas as a mise-en-scène of power and discursive formation, we have illustrated at least two more ways of perceiving Velázquez's craftsmanship. In accordance with the syntagms emerging from our intuition of his mise-en-abime with Rubens and Titian, we perceive that he could have (1) competed with them by staging a so-called revolution; (2) collaborated with them through his contemplations and imitations of their performances. It is suggested that we do not discriminate between these interpretations for a higher or a lower degree of truth and reality. Rather, they make up for a series of positions, actions, or movements that we can try out in order to appreciate the unique design that we spotted on our first encounter with Las Meninas and Fable of Arachne - a close proximity between objects of representation and internal viewers. Such a short distance between them suggests the multiplicity of subjects that we are likely to perceive. It makes the point that several alternative truths as regards a single piece of artwork may coexist within our consciousness - some are apparent while others virtual or obscure.

These concurrent perceptions in response to the same sensory input intriguingly contradict each other since they are governed by different concepts we have acquired in time (Mausfeld 2011: 19-20). Such a human condition - our capacity to juxtapose and dramatize different perceptions and conceptions on the same horizons (congenial to what Saussure and Hegel thought about the heterogeneity of signs) - appears to have been underestimated in the conventional approach to paintings which values some generalized shared features of artworks within specific periods, schools, and areas (Pächt 1999: 132-133; Bergson 2007 [1903-1923]: 157-158, 172-173; Nagel and Pericolo 2010). Measured against this context in which scholars have shown their discontents with certain quantitative criteria in artistic inquiries, the merits of introducing the Saussurean-Hegelian composite approach into our study of paintings are two-fold: (1) it helps regain, expand, and extend our acute perceptions; (2) it exploits the actual paradox underlying our memories and perceptions. This suggested approach serves to revitalize artists and their works from deep inside on our numerous encounters with them. 


\subsection{Shared tendencies of questioning and answering in art history}

Assessed in the context of adopting an evolutionary approach to the arts, the contradictory perceptions we have developed may appear as nerve-racking as the heated debate - should artists be rivals or collaborators? Some old stories told of the survival of artists and their works emphasized the power of artificial selections imposed on creative subjects from the outside. It overlooked the fact that great artists in history can be appreciated as autonomous agents that were able to absorb remarkably from the past while actively formulating their own designs irrespective of external demands. In addition to the problem of concentrated attention on things beyond the artworks, artists' inner needs - certain private and personal aspirations - for selecting things from the outside were underestimated. Such an oversight gave a biased picture of the process of evolution in art history: presuming that evolution is a process of unfolding and revealing the ripening of certain geniuses, some art historians such as Vasari regarded periodization as the standard way of appreciating artists within their specific historical frameworks.

Considering the rich complexity of evolution - full of uncertainties such as regressions, digressions, and mutations - and the constantly renewable nature of attributions in art history, we may wonder whether describing artists and their works in terms of period styles is simply a naïve way of absorbing the evolutionary logic (Panofsky 1972; Pächt 1999). Those tremendous efforts of periodization may well deprive artworks of the chances or possibilities to form interesting dialogues with each other in our living history. It is therefore urgent to revise our way of looking at the arts: rather than anchoring artworks to their specific artists, times, and environments, we should revitalize them as diverse non-adaptive phenomena. Seeing from such a revised position, we would be able to perceive minute details or clusters of features in a non-reductive fashion. In answer to this demand, we derive from Saussure and Hegel the essential idea that all things that are somehow alive function within certain constraints in specific systems. Species and language users are seen not as completely free agents, but rather as social actors that constantly deal with the tension between their inner needs and communal collective rules. Such a premise enables us to overcome certain dogmas of crude evolutionism (such as pure rivalry or the survival the fittest) when discussing the inner evolutionary logic of painterly techniques - Velázquez's approach of creating softness and blurriness later in his career is one of the good examples.

The updated evolutionary approach also advises that we imagine the interactions between agents in different epochs and geographical areas. By employing the technique of comparing and contrasting, we observe how creative agents - 

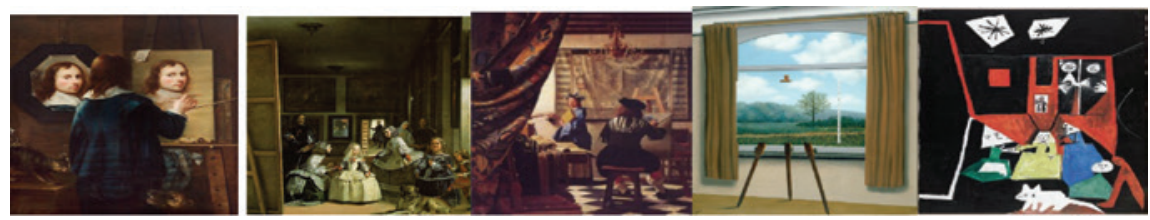

Fig. 6: Some similar schemes of questioning representation (Johannes Gumpp, Self-Portrait, 1646; Diego Velázquez, Las Meninas, 1656; Johannes Vermeer, The Art of Painting, 1666-1667; René Magritte, La Condition Humaine, 1933-1935; Pablo Picasso, a variation on Las Meninas, 1957)

just like organic functions - across systems have cooperated in experimenting with solutions to the problems in their own trades (Gould 1982; Pächt 1999: 135; Bergson 2007 [1903-1923]: 158-159). In the case of Velázquez, we have exposed his intricate scheme as regards the autonomy of painting (as revealed in the images of Arachne, his self-portrait, and the old spinner) in relation to his absorption of the Flemish and the Italian conventions. However, we cannot fully appreciate the meaning of his scheme unless we align his work with those achieved by his successors. The benefit of inserting his work into this new sequence (Figure 6) is once again to expand and extend our perception. We are shown how several artists have engaged with Velázquez's proposition through a couple of similar schemes: they persistently carry on his thoughts into the future. Glancing through this sequence, we no longer feel the pang of conscience that puzzled us at the beginning of the inquiry. We instead experience some pleasure of awakening, recognizing not only the playfulness of an artist depicting himself at work, but also the painterly aesthetic object that is profoundly divided between seeing and thinking.

\section{References}

Benveniste, Emile. 1985 [1969]. The semiology of language. In R. E. Innis (ed.), Semiotics: An introductory anthology, 228-246. Bloomington: Indiana University Press.

Bergson, Henri. 2007 [1903-1923]. Introduction I: Retrograde movement of the true growth of truth. The perception of change. In The creative mind: An introduction to metaphysics, M. L. Andison (trans.), 9-32, 153-186. Mineola: Dover.

Brown, Jonathan \& Garrido, Carmen. 1998. Velázquez: The technique of genius. New Haven \& London: Yale University Press.

De Man, Paul. 1982. Sign and symbol in Hegel's Aesthetics. Critical Inquiry 8(4). 761-775. De Saussure, Ferdinand. 2006. Writings in general linguistics. Oxford \& New York: Oxford University Press. 
Foucault, Michel. 1988. Las Meniñas. In N. Bryson (ed.), Calligram: Essays in new art history from France, 91-105. Cambridge: Cambridge University Press.

Gould, Stephen Jay. 1982. Exaptation - a missing term in the science of form. Paleobiology 8(1). 4-15.

Gross, Charles G. 1999. The medieval cell doctrine of brain function. In Brain, vision, memory: Tales in the history of neuroscience, 31-36. Cambridge \& London: MIT Press.

Hegel, G. W. F. 2010 [1817]. Theoretical mind. In M. Inwood (ed.), W. Wallace \& A. V. Miller (trans.), Philosophy of mind, 173-206. Oxford \& New York: Oxford University Press.

Jakobson, Roman. 1987a. A glance at the development of semiotics. In K. Pomorska \& S. Rudy (eds.), Language in literature, 436-454. Cambridge \& London: Belknap Press of Harvard University Press.

Jakobson, Roman. 1987b. On realism in art. In K. Pomorska \& S. Rudy (eds.), Language in Literature, 19-27. Cambridge \& London: Belknap Press of Harvard University Press.

Jameson, Frederic. 2010. The Hegel variations: On the phenomenology of spirit. London; New York: Verso.

Lassaigne, Jacques. 1952. La peinture espagnole. II. De Velázquez à Picasso. Geneva: Skira.

Lotman, Juri. 2009. The phenomenon of art. In M. Grishakova \& P. Cobley (eds.), W. Clark (trans.), Culture and explosion [Semiotics, Communication and Cognition 1], 150-159. Berlin \& New York: Mouton de Gruyter.

Mausfeld, Rainer. 2011. Intrinsic multiperspectivity: Conceptual forms and the functional architecture of the perceptual system. In W. Welsch, W. Singer \& A. Wunder (eds.), Interdisciplinary anthropology, 19-54. Berlin \& Heidelberg: Springer Verlag.

Merleau-Ponty, Maurice. 1993. Indirect language and the voices of silence. In G. A. Johnson \& M. B. Smith (eds.), The Merleau-Ponty aesthetics reader: Philosophy and painting, 76-120. Evanston: Northwestern University Press.

Nagel, Alexander \& Lorenzo Pericolo. 2010. Unresolved images: An introduction to aporia as an analytical category in the interpretation of early modern art. In A. Nagel \& L. Pericolo (eds.), Subject as aporia in early modern art, 1-15. Farnham: Ashgate.

Nancy, Jean-Luc. 2006. The look of the portrait. In S. Sparks (ed.), Multiple arts: The muses II, 220-247. Stanford: Stanford University Press.

Ovid. 2010. Book VI: Of praise and punishment. In Metamorphoses, C. Martin (trans. \& ed.), 143-167. New York; London: W. W. Norton.

Pächt, Otto. 1999 [1986]. The practice of art history: Reflections on method, D. Britt (trans.). London: Harvey Miller.

Panofsky, Erwin. 1972. Renaissance - self-definition or self-deception? In G. Paulsson (ed.), Renaissance and renascences in Western art, 1-41. New York: Harper \& Row.

Portis-Winner, Irene. 1994. Peirce, Saussure, and Jakobson's aesthetic function: Toward a synthetic view of the aesthetic function. In H. Parret (ed.), Peirce and value theory: On Peircean ethics and aesthetics, 123-142. Amsterdam; Philadelphia: John Benjamins.

Portús, Javier. 2007. Connecting threads: Meninas, spinners, and a musical fable. In J. Portús (ed.), Velázquez's fables, 279-303. Madrid: Museo del Prado.

Puttfarken, Thomas. 2003. Aristotle, Titian, and tragic painting. In D. Arnold \& M. Iversen (eds), Art and thought, 9-27. Oxford: Blackwell.

Puttfarken, Thomas. 2005. Titian's Poesie for Philip II as painted tragedies. In Titian and tragic paintings, 155-181. New Haven \& London: Yale University Press.

Surber, Jere O'Neill. 2006. Introduction. In J. O. Surber (ed.), Hegel and language, 1-31. New York: State University of New York Press. 
Wedmore, Frederick. 1888. Mr. Frederick Wedmore's notes on Velázquez and Titian in the etchings of R. W. Macbeth, ARA. London: Robert Dunthorne.

\section{Bionote}

Jui-Pi Chien (b. 1973) is an associate professor at National Taiwan University $<$ jpchien@ntu.edu.tw>. Her research interests include semiotics and hermeneutics, comparative literature, and comparative aesthetics and the arts. Her publications include "Can Saussure's orangery manuscripts shed new light on biosemiotics?" (2011); "Un mélange genevois: Tacit notions of iconicity in Ferdinand de Saussure's Writings in General Linguistics" (2011); "Matthew Arnold's reception of Hippolyte Taine: Lord Byron as 'touchstone" (2012); and "A glance at the relation between Saussure and aesthetics” (2012). 